\title{
Pricing Currency Options with Intra-Daily
}

\section{Implied Volatility}

\author{
Ariful Hoque ${ }^{1}$ and Petko S. Kalev ${ }^{2}$
}

\begin{abstract}
This paper introduces the intra-daily implied volatility (IDIV), a new volatility measure to price currency option accurately. The IDIV is developed based on the implied volatility estimated on equally spaced intra-daily intervals. This model captures the intra-daily level aggregate information related to foreign exchange (FX) behavior, which changes every five minutes. The implied volatility (IV) and realized volatility (RV) are widely accepted as good estimates of daily and intra-daily price volatility, respectively. Therefore, using the options pricing framework, we assess the capability of IDIV against IV and RV in pricing foreign currency options. A comparison of out-of-sample forecasts under both the F-test and Diebold-Mariano test reveals that the IDIV outperforms both the IV and the RV in estimating one-day-ahead option prices. In other words, the IDIV estimation framework provides a more accurate and efficient volatility estimate for pricing currency options. The findings of this study indicate that the forward looking intra-daily information of IDIV is appropriate to price options correctly rather than forward looking daily and historical intra-daily information is obtained by the IV and RV, respectively.
\end{abstract}

Keywords: Intra-daily implied volatility, realized volatility, currency options pricing

JEL Code(s): G13, G15

\footnotetext{
${ }^{1}$ Murdoch University, Australia. a.hoque@murdoch.edu.au

${ }^{2}$ University of South Australia
} 


\section{Introduction}

To properly price currency options, an accurate prediction of foreign exchange (FX) volatility is crucial. The implied volatility (IV) is widely used as a good estimate of FX volatility for pricing options. However, we argue that the daily-level IV weakens the ability to capture the complete intra-day information, which is essential for accurately forecasting FX movement for pricing options. This study therefore introduces intra-daily implied volatility (IDIV) to obtain whole trading day market aggregate information for pricing currency options with greater accuracy.

In the early research, using data from currency options, Scott and Tucker (1989) find that IV derived from currency options captures nearly 50 percent of the actual currency volatility. When historical volatility is included in the investor's information set, the authors find no evidence of improved predictive accuracy. Jorion (1995) examines the predictive power of IV for the German mark, the Japanese yen and the Swiss franc against the U.S. dollar, traded in the Chicago Mercantile Exchange. Jorion's results suggest that IV outperforms statistical time-series models in terms of information content and predictive power, but it appears to be an upwardly biased estimator of future volatility. $\mathrm{Xu}$ and Taylor (1995) examine the informational efficiency of the currency options market in the Philadelphia Stock Exchange. They study four currencies (the British pound, German mark, Japanese yen and Swiss franc against the U.S. dollar) over the period ranging from January 1985 to January 1991. They find that option prices contain incremental information about future volatilities. Christoffersen and Mazzotta (2005) use over-the-counter (OTC) currency options prices and find that the IV provides largely unbiased and fairly accurate forecasts of one-month-ahead and three-month-ahead actual volatility. Chang and Tabak (2007) present evidence that the IV in option prices contains information that is not present in past returns for the Brazilian exchange rate against the U.S. dollar. Instead of currency options, Frijns et al. (2010) and Kang et al. (2010) analyze stock and stock index options, respectively, and confirm that IV is superior in terms of information content and predictive power.

The above-mentioned studies involving IV often find that all the relevant information for predicting the volatility of an underlying asset can be found in the options price. However, we are particularly interested in FX volatility prediction and argue that IV holds the discrete information regarding the FX movement at a specific time of the trading day. Therefore, the daily-level IV is not sufficient for estimating accurate options prices. For example, the IV based on the closing options price information of trading day $t$ might not be an appropriate performance measurement for forecasting the opening or midday options price on trading day $t+1$. Therefore, we develop the IDIV model to capture the intra-daily-level aggregate information related to FX behavior, which changes every five minutes, to correctly estimate one-day-ahead currency options prices.

This study provides two major contributions to the literature. First, while IV is widely used to predict FX volatility, to the best of our knowledge, IDIV has not yet been explored as a method for forecasting FX volatility for pricing options. Second, Pong et al. (2004) show that a forecast based on RV provides superior accuracy relative to a forecast based on IV. Martin and Zein (2004) present similar results for equity and commodities in addition to currency. It is inappropriate to compare, however, the forecasting capability of realized volatility (RV) and IV since each of these is constructed with different levels of data. Our study evaluates the performance differences between RV and IDIV, based on the same level of intra-daily FX return. 
We find that IDIV outperforms IV for pricing options. Further, the outstanding performance of IDIV against RV substantiates its ability for pricing options. This also indicates that the RV contains intra-daily historical information that is not as appropriate for accurately forecasting price options as the information obtained from the IDIV. The paper is organized as follows. Section 2 presents the research methodology. Section 3 describes the data used in this study and Section 4 provides an empirical analysis. Section 5 summarizes the findings and offers conclusions.

\section{Methodology}

This study's methodology consists of two primary steps: (i) estimate the IDIV, IV and RV; (ii) forecast options price using volatilities obtained in step (i) as input for the pricing model and to measure forecast pricing error.

\subsection{Estimate Volatilities}

The following sub-sections discuss the IDIV, IV and RV estimation methods used in this study.

\section{Intra-daily implied volatility}

To calculate IDIV, first we obtain IV at the intra-daily level using Equations (A3) and (A4) from the Appendix for call (C) and put (P) option, respectively. Chou et al. (2011) find a clear link between the level of IV curve and options liquidity. Further, Nordẻn and Xu (2012) show that the option "happiness" (the steepness of the volatility smirk) is significantly dependent on the options liquidity. Since the call and put options transaction volume (liquidity) is different within the five-minute (5-min) frequency period, the annualized IDIV is computed as the weighted average of call and put IV in Equation (1):

$\sigma_{t}^{I D I V}=\sum_{i=1}^{n} w_{C, i} \sigma_{C, i}+w_{P, i} \sigma_{P, i}$

where $n$ is the total number of intervals between 9:30 AM and 4:00 PM on trading day $t$. In Equation (1), $w_{C, i}$ and $w_{P, i}$ denote the call and put IDIV weights, respectively, for the 5min interval. For each interval, $w_{C, i}$ is calculated as the total number of call transactions divided by the sum of the total number of call and put transactions (i.e., the total number of call is divided by sum of the total number of call and put). Similarly, for each interval $w_{P, i}$ is calculated as the total number of put transactions divided by the sum of the total number of call and put transactions (i.e., the total number of put $\div$ ((total number of call + total number of put)). The sum of $w_{C, i}$ and $w_{P, i}$ is equal to 1 .

\section{Implied volatility}

Gospodinov et al. (2006) suggest that an unbiased IV can be extracted from near-the-money options. DATASTREAM provides the call implied daily volatility $\sigma_{C, t}$ and put IV $\sigma_{P, t}$, These are interpolated using the two nearest at-the-money (ATM) options series - one above and one below the underlying FX in the financial system software developed by MB Risk Management ${ }^{1}$. Jorion (1995) computes IV as the arithmetic average obtained from the two closest ATM call and put options. Thus, this study estimates the annualized IV on any given day $t$ as the arithmetic average of $\sigma_{C, t}$ and $\sigma_{P, t}$, 
$\sigma_{t}^{I V}=\frac{\sigma_{C, t}+\sigma_{P, t}}{2}$

\section{Realized volatility}

The RV is constructed by summing the squared intra-daily returns sampled at a particular frequency. The optimal frequency for constructing RV is unknown. Following standard

\footnotetext{
${ }^{1}$ The MB Risk Management developed the world-famous UNIVERSAL Add-ins ${ }^{\circledR}$. With 30,000+ users worldwide, UNIVERSAL Add-ins is the most widely used derivative software for the pricing, risk management, trading, arbitrage, fund management and auditing of securities, options, futures and swaps in the convertible, fixed income, commodities, energy, equities, FX and money markets (see more at website http://www.mbrm.com).
}

practice, the RV series is constructed using a 5-min sampling frequency. If $S_{i}$ is the exchange rate for the 5-min sampling frequency, the underlying exchange rate return in the 5-min interval is estimated as:

$r_{i}=\ln \left(\frac{s_{i}}{s_{i-1}}\right)$

The realized variance of day $\mathrm{t}$ is computed as:

$v_{t}=\sum_{i=1}^{n} r_{i}^{2}$

Where $n$ is the total number of intervals from 9:30 AM to 4:00 PM on the trading day. Since $\mathrm{RV}$ is the standard deviation of the realized variance, the annualized RV for trading day $t$ is:

$\sigma_{t}^{R V}=\sqrt{D v_{t}}$

where D is 252 trading days per year, consistent with the normal assumption of the options market.

\subsection{Measuring Forecast Pricing Error}

To forecast one-day-ahead opening, midday and closing $\mathrm{C}$ and $\mathrm{P}$ option prices, Equation (4) is developed using the MATLAB built-in function "blsprice," which embeds Equations (A1) and (A2) from the appendix:

$|C, P|_{t}^{m}=\operatorname{blsprice}\left(S_{t}, X_{t}, R_{t}^{d}, T, \sigma_{t-1}^{m}, R_{t}^{f}\right)$, 
where, $\forall_{m}=I D I V, I V, R V$.

Further, if $\pi_{t}$ denotes the difference between the forecasted options price and market options price, the mean square pricing error for $n$ number of observations is:

$M S P E_{j}=\frac{1}{n} \sum_{t=1}^{n} \pi_{t, j}^{2}$,

where $\forall_{j}=C, P$.

Next, the F-test is modeled as:

$F_{j}^{l, I D I V}=\frac{M S P E_{j}^{l}}{M S P E_{j}^{I D I V}}$,

where, $\forall_{l}=I V, R V$. The null hypothesis $H_{0}: M S P E_{j}^{l}=M S P E_{j}^{I D I V}$ is tested against the alternative hypothesis $H_{A}: M S P E_{j}^{l}>M S P E_{j}^{I D I V}$.

The mean squared pricing error (MSPE) criterion under the F-test compares the options price forecasting performance of IDIV against IV and RV. Therefore, it is important to test whether the pricing error of IDIV is statistically different from that of IV and RV. Diebold and Mariano (1995) propose a test statistic that there is no difference in the accuracy of two competing forecasts. In the Diebold and Mariano (DM) test, the mean differential loss from $\left(\pi_{t, j}^{l}\right)^{2}$ and $\left(\pi_{t, j}^{I D I V}\right)^{2}$ is estimated as:

$\bar{d}=\frac{1}{n} \sum_{t=1}^{n}\left|\left(\pi_{t, j}^{l}\right)^{2}-\left(\pi_{t, j}^{I D I V}\right)^{2}\right|$.

Under the null hypothesis of the accuracy of the equal one-day-ahead pricing error, the value of $\overline{\mathrm{d}}$ is zero. The DM statistic is given by:

$D M_{j}^{l, I D I V}=\frac{\bar{d}}{\sqrt{\operatorname{var}(\bar{d})}}$,

where, $\operatorname{var}(\bar{d})=\frac{1}{n-1} \operatorname{var}\left(d_{t}\right)$. Equation (6) follows a t-distribution with $(n-1)$ degrees of freedom.

\section{Data}

Using data obtained from the options price reporting authority, this study analyzes the six major European currency options: the Australian dollar (AUD), Canadian dollar (CAD), Swiss franc (CHF), Euro (EUR), British pound (GBP) and Japanese yen (JPY). These options are traded in Philadelphia Stock Exchange (PHLX) from 9:30 AM to 4:00 PM (US Eastern Standard Time) in each trading day and registered as World Currency Options. The sample options expire on Saturday following the third Friday of the expiration month and settle in UD dollar. The sample period starts on December 21, 2009 for all currency except AUD, 
which begins $21 / 06 / 2010$. The difference in start dates is due to the unavailability of the AUD put-call pair from 21/12/2009 (Monday) to 18/06/2010 (Friday). The sample period for all currencies in this study ends on 27/05/2011. Consequently, the AUD sample period includes 238 trading days, whereas the remaining currency options are sampled for 362 trading days. In this study, the intra-daily and daily data are obtained from SIRCA and DATASTREAM, respectively.

The intra-daily data from the SIRCA database consist of call, put, strike and spot price transactions at 5-min intervals in each trading day. The high-frequency intra-daily-level data analysis appears in Table 1. The sample currency names are given in the first column. The information in Panel A describes the construction of a put-call pair for IDIV. Column 3 and Column 4 of Panel A present the 5-min interval for "total transaction" and "sample transaction," respectively. For the "total transaction," the 5-min interval put-call pair holds one or more transactions. Therefore, the "sample transaction" is constructed by filtering the "total transaction" that has only one put-call pair in the 5-min interval. In last column, the "average daily transaction" is computed as the "sample transaction" divided by the "trading days" from Column 2. The average daily transaction should be 79 for the 9:30 AM to 4:00 PM trading hours. For all currencies, an "average daily transaction" of less than 79 indicates that some of the 5-min intervals do not have a put-call pair transaction.

\section{Table 1: SIRCA intra-daily data analysis}

Currency Panel A: Put-call pair data set for IDIV

\begin{tabular}{|c|c|c|c|c|}
\hline & Trading days & Total transaction & Sample transaction & Average daily transaction \\
\hline AUD & 238 & $1,092,604$ & 18,078 & 76 \\
\hline CAD & 362 & $1,483,583$ & 25,967 & 72 \\
\hline $\mathrm{CHF}$ & 362 & $1,079,024$ & 24,456 & 68 \\
\hline EUR & 362 & $2,769,536$ & 26,129 & 72 \\
\hline GBP & 362 & $1,571,583$ & 25,050 & 69 \\
\hline \multirow[t]{4}{*}{ JPY } & 362 & $1,332,328$ & 24,394 & 67 \\
\hline & \multicolumn{4}{|c|}{ Panel B: Spot price data set for RV } \\
\hline & \multicolumn{2}{|c|}{$\begin{array}{l}\text { Data set (i) } \\
\text { FX return for 5-min interval }\end{array}$} & \multicolumn{2}{|c|}{$\begin{array}{c}\text { Data set (ii) } \\
\text { FX return for 5-min interval that matches the put- } \\
\text { call pair transaction }\end{array}$} \\
\hline & Total FX return & Average daily FX return & Total FX return & Average daily FX return \\
\hline AUD & 16,898 & 71 & 16,234 & 68 \\
\hline CAD & 25,670 & 71 & 22,773 & 63 \\
\hline $\mathrm{CHF}$ & 25,695 & 71 & 21,294 & 59 \\
\hline EUR & 25,695 & 71 & 23,233 & 64 \\
\hline GBP & 25,695 & 71 & 21,758 & 60 \\
\hline JPY & 25,695 & 71 & 21,478 & 59 \\
\hline
\end{tabular}

The information in Panel B defines two different spot price data sets for RV: (i) the FX return for a transaction at the 5-min interval, and (ii) the FX return for a transaction at the 5-min interval that matches the put-call pair transaction. For data set (i), the "average daily FX return" is calculated as the "total FX return" in Column 2 divided by the "trading days" from Column 2 of Panel A. Similarly, the "average daily FX return" of data set (ii) is computed using the "total FX return" in Column 4 and the "trading days" from Column 2 of Panel A. For all currencies, data set (i) provides an "average daily FX return" of 71 (5 from 9:30 AM to 10:00 AM and 11 for each hour from 10:00 AM to 4:00 PM. Since data set (ii) is constructed with matching put-call pair transactions and some of the 5-min intervals do not 
have a put-call pair transaction (as reported in Panel A), the "average daily FX return" of data set (ii) is less than that of data set (i) for all sample currencies. Data set (ii) will be used to conduct a robustness test for IDIV and RV pricing options.

Intra-daily data obtained from SIRCA are also used to determine the opening, midday and closing options market prices. The first available 5-min interval price between 9:30 AM and 10:00 AM is considered to be the "opening price." Similarly, the period from 12:30 PM to 1:00 PM is used to pick up the first available 5-min interval price and is considered to be the "midday price." The "closing price" includes the first 5-min interval price between 3:30 PM and 4:00 PM.

The daily data obtained from DATASTREAM consist of the nearest daily ATM call and put IV and the risk-free closing domestic and foreign interest rates. The daily nearest ATM strike and spot price is also obtained in order to assess the quality of the daily DATASTREAM interpolated IV for call options (call-IV) and IV for put options (put-IV). The descriptive statistics of strike price, spot price, call-IV and put-IV appear in Table 2. The mean values of the strike price and the spot price are the same for all currencies. Furthermore, the median values for the strike price and the spot price are quite similar. Therefore, we conclude that the DATASTREAM interpolated call-IV and put-IV using currency options are traded at the nearest ATM. The information in Column 5 and Column 6 provides the mean and median of the call-IV and put-IV, respectively. Whaley (1986) shows that call-IV is, on average, lower than put-IV. We find similar results for the AUD, BP and CAD options (for example, for AUD the mean of the call-IV and the put-IV is 12.92 percent and 12.98 percent, respectively).

Table 2: DATASTREAM daily data descriptive analysis

\begin{tabular}{llllll}
\hline Currency & Statistical & \multicolumn{4}{c}{ Variables } \\
\cline { 3 - 6 } & measures & Strike price & Spot price & Call IV & Put IV \\
\hline AUD & Mean & 97.9225 & 97.9182 & 0.1292 & 0.1298 \\
& Median & 99.0000 & 98.9900 & 0.1263 & 0.1267 \\
$\mathrm{BP}$ & Mean & 156.6445 & 156.6639 & 0.1083 & 0.1085 \\
& Median & 157.5000 & 157.3400 & 0.1056 & 0.1061 \\
$\mathrm{CAD}$ & Mean & 98.5360 & 98.5386 & 0.1065 & 0.1068 \\
& Median & 98.0000 & 98.1100 & 0.1053 & 0.1056 \\
$\mathrm{EUR}$ & Mean & 134.8960 & 134.8849 & 0.1211 & 0.1204 \\
& Median & 136.0000 & 135.8200 & 0.1181 & 0.1166 \\
$\mathrm{JPY}$ & Mean & 116.1791 & 116.1800 & 0.1149 & 0.1131 \\
& Median & 118.1800 & 118.0000 & 0.1131 & 0.1107 \\
$\mathrm{SF}$ & Mean & 99.76667 & 99.7551 & 0.1130 & 0.1118 \\
& Median & 98.5000 & 0.1115 & 0.1104 \\
& \multicolumn{5}{l}{} \\
\hline \multicolumn{5}{l}{ Note: Each currency sample size is 362, except AUD, which is 238. } \\
\hline
\end{tabular}

\section{Empirical Analysis}

The empirical analysis in this study is carried out in three steps: (i) forecast one-day-ahead opening, midday and closing options prices, as in Equation (4); (ii) conduct an F-test using Equation (5) to compare the MSPE equality for IDIV against that of IV and RV; (iii) perform a DM-test using Equation (6) to determine whether the MSPE for IDIV is statistically different from that of IV and RV. 
Table 3 provides an analysis of the IV and IDIV opening, midday and closing options price forecasting errors as noted in Panels A, B and C, respectively. The results are presented as the "call MSPE equality test" (Columns 2-4), the "put MSPE equality test" (Columns 5-7) and the DM-test (Columns 8 and 9). For all currencies listed in Panel A, the F-values in Columns 4 and 7 indicate that $\operatorname{MSPE}_{\mathrm{C}}^{\mathrm{IV}}$ (Column 2) and MSPE $\mathrm{P}_{\mathrm{P}}^{\mathrm{IV}}$ (Column 5) are larger than

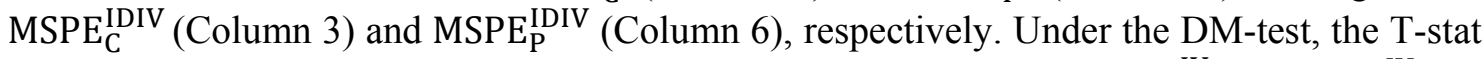
values for the call and the put in Columns 8 and 9 reveal that MSPE $\mathrm{C}_{\mathrm{C}}^{\mathrm{IV}}$ and MSPE $\mathrm{P}_{\mathrm{P}}^{\mathrm{IV}}$ are statistically different from MSPE ${ }_{C}^{I D I V}$ and MSPE IDIV , respectively. Furthermore, the positive T-stat values suggest that $\mathrm{MSPE}_{\mathrm{c}}^{\mathrm{IV}}$ and $\mathrm{MSPE}_{\mathrm{p}}^{\mathrm{IV}}$ have a greater value than $\mathrm{MSPE}_{\mathrm{C}}^{\mathrm{IDIV}}$ and MSPEIDIV, respectively. Panel $\mathrm{B}$ and Panel $\mathrm{C}$ provide similar results for all sample currencies. The consistent findings in the series of F-tests and DM-tests for the opening, midday and closing prices across the six major currency options confirm that the FX forecasting capability of IDIV is better than the FX forecasting capability of IV for pricing one-day-ahead options.

Table 3: IV and IDIV price forecasting error analysis

\begin{tabular}{|c|c|c|c|c|c|c|c|c|}
\hline \multirow[t]{2}{*}{ Currency } & \multicolumn{3}{|c|}{ Call MSPE equality test } & \multicolumn{3}{|c|}{ Put MSPE equality test } & \multicolumn{2}{|c|}{ DM-test } \\
\hline & $\mathrm{MSPE}_{\mathrm{C}}^{\mathrm{IV}}$ & MSPEE $_{C}^{\text {IDIV }}$ & F-value & $\mathrm{MSPE}_{\mathrm{P}}^{\mathrm{IV}}$ & MSPE $_{P}^{I D I V}$ & F-value & call T-stat & put T-stat \\
\hline \multicolumn{9}{|c|}{ Panel A: Opening price } \\
\hline AUD & 5.2743 & 5.2313 & 1.0082 & 25.9839 & 25.8966 & 1.0034 & 9.5399 & 9.3878 \\
\hline CAD & 7.3257 & 7.2887 & 1.0051 & 9.4870 & 9.4445 & 1.0045 & 7.8145 & 8.2976 \\
\hline $\mathrm{CHF}$ & 7.6913 & 7.6468 & 1.0058 & 7.0686 & 7.0600 & 1.0012 & 11.9152 & 11.9864 \\
\hline EUR & 14.8366 & 14.7573 & 1.0054 & 17.0006 & 16.9149 & 1.0051 & 8.0578 & 8.1490 \\
\hline GBP & 18.7107 & 18.5527 & 1.0085 & 22.0190 & 21.8448 & 1.0079 & 9.4046 & 9.5882 \\
\hline JPY & 13.8257 & 13.7447 & 1.0059 & 12.7390 & 12.6592 & 1.0063 & 9.1232 & 9.7135 \\
\hline \multicolumn{9}{|c|}{ Panel B: Midday price } \\
\hline AUD & 7.1359 & 7.0492 & 1.0122 & 34.1578 & 33.9698 & 1.0055 & 17.4849 & 16.9195 \\
\hline CAD & 6.8944 & 6.8466 & 1.0070 & 8.9431 & 8.8883 & 1.0062 & 10.3940 & 10.8576 \\
\hline $\mathrm{CHF}$ & 8.0847 & 8.0429 & 1.0052 & 7.3411 & 7.3017 & 1.0054 & 11.7083 & 11.6739 \\
\hline EUR & 17.8007 & 17.7213 & 1.0045 & 20.4471 & 20.3622 & 1.0042 & 7.6674 & 7.6753 \\
\hline GBP & 21.4880 & 21.2938 & 1.0091 & 25.8580 & 25.6420 & 1.0084 & 9.9064 & 10.6304 \\
\hline JPY & 12.9831 & 12.8991 & 1.0065 & 11.5282 & 11.4474 & 1.0071 & 11.2861 & 12.0425 \\
\hline
\end{tabular}

Panel C: Closing price

\begin{tabular}{lllllllll}
\hline AUD & 6.2164 & 6.1527 & 1.0103 & 29.3182 & 29.1833 & 1.0046 & 13.4448 & 12.7952 \\
CAD & 5.6911 & 5.6625 & 1.0051 & 7.4113 & 7.3784 & 1.0045 & 7.0728 & 7.4112 \\
CHF & 6.6487 & 6.6249 & 1.0036 & 5.9851 & 5.9624 & 1.0038 & 8.6526 & 8.7788 \\
EUR & 14.7981 & 14.7461 & 1.0035 & 16.7089 & 16.6544 & 1.0033 & 6.1969 & 6.1210 \\
GBP & 18.3212 & 18.1856 & 1.0075 & 22.4589 & 22.3115 & 1.0066 & 8.5613 & 8.5507 \\
JPY & 11.1949 & 11.1480 & 1.0042 & 10.0344 & 9.9894 & 1.0045 & 5.5880 & 5.7238
\end{tabular}

Notes: MSPE denotes the mean square pricing error. T-stat represents the T-statistic of the DM-test. The F-test critical value is 1 for the F-distribution with more than 120 degrees of freedom for both numerator and denominator. 
Next, the RV and IDIV opening, midday and closing options price forecasting error analysis results appear in Panels A, B and C, respectively, of Table 4. Note that RV is estimated using the intra-daily-level data set (i) in Panel B (Table 1). The data population structure of Table 4 is the same as Table 3. For all currencies in Panels A, B and C, the F-test results show that $\mathrm{MSPE}_{\mathrm{C}}^{\mathrm{RV}}$ and $\mathrm{MSPE}_{\mathrm{P}}^{\mathrm{RV}}$ have a larger value than $\mathrm{MSPE}_{\mathrm{C}}^{\mathrm{IDIV}}$ and $\mathrm{MSPE}_{\mathrm{P}}^{\mathrm{IDIV}}$, respectively. Similar results are found using the DM-test. The F-test and DM-test results are consistent across the six major currency options, implying that IDIV outperforms RV for forecasting FX volatility for the next-day options price.

\begin{tabular}{|c|c|c|c|c|c|c|c|c|}
\hline \multicolumn{9}{|c|}{ Table 4: RV and IDIV price forecasting error analysis } \\
\hline \multirow[t]{2}{*}{ Currency } & \multicolumn{3}{|c|}{ Call MSPE equality test } & \multicolumn{3}{|c|}{ Put MSPE equality test } & \multicolumn{2}{|c|}{ DM-test } \\
\hline & $\mathrm{MSPE}_{\mathrm{C}}^{\mathrm{RV}}$ & $\mathrm{MSPE}_{\mathrm{C}}^{\mathrm{IDIV}}$ & F-value & $\mathrm{MSPE}_{\mathrm{P}}^{\mathrm{RV}}$ & MSPE $_{P}^{\text {IDIV }}$ & F-value & call T-stat & put T-stat \\
\hline \multicolumn{9}{|c|}{ Panel A: Opening price } \\
\hline $\begin{array}{l}\text { AUD } \\
\text { CAD } \\
\text { CHF } \\
\text { EUR } \\
\text { GBP } \\
\text { JPY }\end{array}$ & $\begin{array}{l}5.5285 \\
7.5286 \\
7.9335 \\
15.5463 \\
19.2377 \\
14.3154\end{array}$ & $\begin{array}{l}5.2313 \\
7.2887 \\
7.6468 \\
14.7573 \\
18.5527 \\
13.7447\end{array}$ & $\begin{array}{l}1.0568 \\
1.0329 \\
1.0375 \\
1.0535 \\
1.0369 \\
1.0415\end{array}$ & $\begin{array}{l}26.4930 \\
9.7186 \\
7.2921 \\
17.7527 \\
22.5852 \\
13.2094\end{array}$ & $\begin{array}{l}25.8966 \\
9.4445 \\
7.0160 \\
16.9149 \\
21.8448 \\
12.6592\end{array}$ & $\begin{array}{l}1.0230 \\
1.0290 \\
1.0394 \\
1.0495 \\
1.0339 \\
1.0435\end{array}$ & $\begin{array}{l}19.4517 \\
16.8712 \\
21.3842 \\
23.0678 \\
14.9149 \\
19.8493\end{array}$ & $\begin{array}{l}18.6189 \\
16.9788 \\
21.6257 \\
23.0176 \\
14.9991 \\
19.7390\end{array}$ \\
\hline \multicolumn{9}{|c|}{ Panel B: Midday price } \\
\hline $\begin{array}{l}\text { AUD } \\
\text { CAD } \\
\text { CHF } \\
\text { EUR } \\
\text { GBP } \\
\text { JPY }\end{array}$ & $\begin{array}{l}7.5904 \\
7.1135 \\
8.3639 \\
17.7213 \\
22.2465 \\
13.5390\end{array}$ & $\begin{array}{l}7.0492 \\
6.8466 \\
8.0429 \\
16.6586 \\
21.2938 \\
12.8991\end{array}$ & $\begin{array}{l}1.0768 \\
1.0389 \\
1.0399 \\
1.0637 \\
1.0447 \\
1.0496\end{array}$ & $\begin{array}{l}35.1089 \\
9.1914 \\
7.6087 \\
21.3572 \\
26.6756 \\
12.0570\end{array}$ & $\begin{array}{l}33.9698 \\
8.8883 \\
7.3017 \\
20.3622 \\
25.6420 \\
11.4474\end{array}$ & $\begin{array}{l}1.0335 \\
1.0341 \\
1.0420 \\
1.0489 \\
1.0403 \\
1.0533\end{array}$ & $\begin{array}{l}33.2099 \\
18.4539 \\
23.0535 \\
26.6625 \\
21.3498 \\
21.7424\end{array}$ & $\begin{array}{l}30.9616 \\
18.8550 \\
22.9202 \\
26.3024 \\
21.3317 \\
21.8637\end{array}$ \\
\hline \multicolumn{9}{|c|}{ Panel C: Closing price } \\
\hline $\begin{array}{l}\text { AUD } \\
\text { CAD } \\
\text { CHF } \\
\text { EUR } \\
\text { GBP } \\
\text { JPY }\end{array}$ & $\begin{array}{l}6.5454 \\
5.8566 \\
6.8360 \\
15.4083 \\
18.8586 \\
11.5676\end{array}$ & $\begin{array}{l}6.1527 \\
5.6625 \\
6.6249 \\
14.7461 \\
18.1856 \\
11.1480\end{array}$ & $\begin{array}{l}1.0638 \\
1.0342 \\
1.0319 \\
1.0449 \\
1.0370 \\
1.0376\end{array}$ & $\begin{array}{l}29.9799 \\
7.5976 \\
6.1652 \\
17.3507 \\
23.0416 \\
10.3940\end{array}$ & $\begin{array}{l}29.1833 \\
7.3784 \\
5.9624 \\
16.6544 \\
22.3115 \\
9.9894\end{array}$ & $\begin{array}{l}1.0272 \\
1.0297 \\
1.0340 \\
1.0418 \\
1.0327 \\
1.0405\end{array}$ & $\begin{array}{l}22.9721 \\
14.9683 \\
16.5124 \\
19.5402 \\
15.3695 \\
15.2149\end{array}$ & $\begin{array}{l}21.7419 \\
15.2571 \\
16.5825 \\
19.1298 \\
15.5173 \\
15.2832\end{array}$ \\
\hline
\end{tabular}

Notes: MSPE denotes the mean square pricing error. T-stat represents the T-statistic of the DM-test. The F-test critical value is 1 for the F-distribution with more than 120 degrees of freedom for both numerator and denominator.

Finally, RV is estimated using intra-daily data set (ii) in Panel B (Table 1) to conduct the RV and IDIV price forecasting error robustness test. The test results are presented in Table 5. The construction and results interpretation of Table 5 are similar to those of Table 4. The overall F-test and DM-test results are consistent with the results reported in Table 4. This indicates that the robustness test results substantiate the statement that IDIV is superior to RV for forecasting FX movement for the one-day-ahead options price. 
Hoque \& Kalev | Pricing Currency Options with Intra-Daily Implied Volatility

Table 5: RV and IDIV price forecasting error robustness test

\begin{tabular}{|c|c|c|c|c|c|c|c|c|}
\hline \multirow[t]{2}{*}{ Currency } & \multicolumn{3}{|c|}{ Call MSPE equality test } & \multicolumn{3}{|c|}{ Put MSPE equality test } & \multicolumn{2}{|c|}{ DM-test } \\
\hline & $\mathrm{MSPE}_{\mathrm{C}}^{\mathrm{RV}}$ & MSPE $_{C}^{\text {IDIV }}$ & F-value & $\mathrm{MSPE}_{\mathrm{P}}^{\mathrm{RV}}$ & MSPE $_{\mathrm{P}}^{\text {IDIV }}$ & F-value & Call T-stat & Put T-stat \\
\hline \multicolumn{9}{|c|}{ Panel A: Opening price } \\
\hline AUD & 5.5357 & 5.2313 & 1.0582 & 26.5080 & 25.8966 & 1.0236 & 19.2329 & 18.3708 \\
\hline CAD & 7.5519 & 7.2887 & 1.0361 & 9.7446 & 9.4445 & 1.0318 & 16.5232 & 16.7603 \\
\hline $\mathrm{CHF}$ & 7.9802 & 7.6468 & 1.0435 & 7.3372 & 7.0160 & 1.0458 & 21.2098 & 21.3645 \\
\hline EUR & 15.5962 & 14.7573 & 1.0568 & 17.8077 & 16.9149 & 1.0528 & 22.6940 & 22.6634 \\
\hline GBP & 19.3464 & 18.5527 & 1.0428 & 22.7035 & 21.8448 & 1.0393 & 14.6664 & 14.7602 \\
\hline JPY & 14.3658 & 13.7447 & 1.0452 & 13.2579 & 12.6592 & 1.0473 & 19.6787 & 19.5545 \\
\hline \multicolumn{9}{|c|}{ Panel B: Midday price } \\
\hline AUD & 7.5948 & 7.0492 & 1.0123 & 35.1182 & 33.9698 & 1.0338 & 32.9025 & 30.7635 \\
\hline CAD & 7.1394 & 6.8466 & 1.0428 & 9.2213 & 8.8883 & 1.0375 & 17.9187 & 18.3094 \\
\hline $\mathrm{CHF}$ & 8.4037 & 8.0429 & 1.0449 & 7.6465 & 7.3017 & 1.0472 & 23.9086 & 23.6150 \\
\hline EUR & 18.7023 & 17.7213 & 1.0554 & 21.4028 & 20.3622 & 1.0511 & 26.5877 & 26.2819 \\
\hline GBP & 22.3774 & 21.2938 & 1.0509 & 26.8193 & 25.6420 & 1.0459 & 20.9945 & 20.9755 \\
\hline JPY & 13.5767 & 12.8991 & 1.0525 & 12.0918 & 11.4474 & 1.0563 & 21.4573 & 21.6658 \\
\hline \multicolumn{9}{|c|}{ Panel C: Closing price } \\
\hline AUD & 6.5528 & 6.1527 & 1.0650 & 29.9951 & 29.1833 & 1.0278 & 22.5900 & 21.4032 \\
\hline CAD & 5.8846 & 5.6625 & 1.0392 & 7.6292 & 7.3784 & 1.0339 & 14.2715 & 14.5969 \\
\hline $\mathrm{CHF}$ & 6.8589 & 6.6249 & 1.0353 & 6.1871 & 5.9624 & 1.0377 & 16.5279 & 16.5772 \\
\hline EUR & 15.4360 & 14.7461 & 1.0468 & 17.3802 & 16.6544 & 1.0436 & 19.4010 & 19.0036 \\
\hline GBP & 18.9370 & 18.1856 & 1.0413 & 23.1273 & 22.3115 & 1.0366 & 15.3159 & 15.4493 \\
\hline JPY & 11.5964 & 11.1480 & 1.0402 & 10.4203 & 9.9894 & 1.0431 & 15.0294 & 15.1756 \\
\hline
\end{tabular}

Notes: MSPE denotes the mean square pricing error. T-stat represents the T-statistic of the DM-test. The F-test critical value is 1 for the F-distribution with more than 120 degrees of freedom for both numerator and denominator.

\section{Conclusion}

Predicting FX volatility for pricing options is critical. In the literature, the IV is considered to be a good estimator of exchange rate volatility. Since the IV contains information for a specific time of the trading day, the IDIV is modeled to accurately capture intra-daily trading day information for pricing options. The IDIV and IV are used as inputs for the Merton version of the Black-Scholes model, which is used to estimate the one-day-ahead options price. The MSPE for IDIV and IV is calculated as the difference between the options market price and the options forecasted price using IDIV and IV, respectively. Under the F-test and the DM-test, the smaller MSPE for IDIV indicates that IDIV outperforms IV for pricing options.

The forecasting performance differences between IDIV and IV might be arguable since the IDIV and the IV contain different levels of market information; the IDIV contains intra-daily information, whereas the IV contains daily-level information. To address this argument, the RV is used as a benchmark to compare the forecasting power of IDIV for pricing options. The RV is constructed based on two different sets of intra-daily-level data: (i) FX returns for 5-min intervals, and (ii) FX returns for 5-min intervals that are matched with the put-call pair frequency. For both data sets, the F-test and the DM-test confirm that 
IDIV is also superior to RV for pricing options since the MSPE for RV has a larger value than the MSPE for IDIV.

We argue that the IDIV contains information about the future dynamics of the currency options price. Fleming at el. (1995) developed the CBOE Market Volatility Index (VIX) based on index options and the IV of both call and put options with the intent of increasing the amount of information incorporated into the index. VIX has since become the most successful method of measuring the volatility in the financial market. The ability of IDIV to obtain information on currency options prices can be improved by integrating the underlying concept of the VIX model with our proposed approach in this study. We have left this problem for future research.

\section{References}

Biger, N., \& Hull, J. (1983). The valuation of currency options. Financial Management, 2, 24-28. http://dx.doi.org/10.2307/3664834

Black, F., \& Scholes, M. (1973). The pricing of options and corporate liabilities. Journal of Political Economy, 83, 637-705. http://dx.doi.org/10.1086/260062

Chang, E. J., \& Tabak, B. M. (2007). Are implied volatilities more informative? The Brazilian real exchange rate case. Applied Financial Economics, 17, 569-576. http://dx.doi.org/10.1080/09603100600706758

Chou, R. K., Chung, S., Hsiao, Y., \& Wang, Y. (2011). The impact of liquidity on option prices. The Journal of Futures Markets, 31, 1116-1141. http://dx.doi.org/10.1002/fut.20531

Christoffersen, P., \& Mazzotta, S. (2005). The accuracy of density forecasts from foreign exchange options. Journal of Financial Econometrics, 3, 578-605. http://dx.doi.org/10.1093/jjfinec/nbi021

Diebold, F. X., \& Mariano, R. S. (1995). Comparing predictive accuracy. Journal of Business and Economic Statistics, 13, 253-263.

Fleming, J., Ostdiek, B., \& Whaley, R. E. (1995). Predicting stock market volatility: A new measure. The Journal of Futures Markets, 15, 265-302. http://dx.doi.org/10.1002/fut.3990150303

Frijns, B., Tallau, C., \& Tourani-Rad, A. (2010). The information content of implied volatility: Evidence from Australia. The Journal of Futures Markets, 30, 134-155.

Gospodinov, N., Gavala, A., \& Jiang, D. (2006). Forecasting volatility. Journal of Forecasting, 25, 381-400. http://dx.doi.org/10.1002/for.993

Jorion, P. (1995). Predicting volatility in the foreign exchange market. Journal of Finance, 50, 507-528. http://dx.doi.org/10.1111/j.1540-6261.1995.tb04793.x

Kang, B. J., Kim, T. S., \& Yoon, S. (2010). Information content of volatility spreads. The Journal of Futures Markets, 30, 533-558.

Martens, M., \& Zein, J. (2004). Predicting financial volatilities: High-frequency time-series forecasts vis-à-vis implied volatility. The Journal of Futures Market, 24, 1005-1028. http://dx.doi.org/10.1002/fut.20126

Merton, R. C. (1973). Theory of rational option pricing. The Bell Journal of Economics and Management Science, 4, 141-183. http://dx.doi.org/10.2307/3003143

Nordẻn, L., \& Xu, C. (2012). Option happiness and liquidity: Is the dynamics of the volatility smirk affected by relative option liquidity? The Journal of Futures Markets, 32, 4774. http://dx.doi.org/10.1002/fut.20507

Pong, S., Shackleton, M. B., Taylor, S. J., \& Xu, X. (2004). Forecasting currency volatility: A comparison of implied volatility and AR(FI)MA models. Journal of Banking and 
Finance, 28, 2541-2563. http://dx.doi.org/10.1016/j.jbankfin.2003.10.015

Scott, E., \& Tucker, A. L. (1989). Predicting currency return volatility. Journal of Banking and Finance, 13, 839-851. http://dx.doi.org/10.1016/0378-4266(89)90005-8

Whaley, R. E. (1986). Valuation of American futures options: Theory and empirical tests. Journal of Finance, 41, 127-150. http://dx.doi.org/10.1111/j.15406261.1986.tb04495.x

Xu, X., \& Taylor, S. J. (1995). Conditional volatility and the informational efficiency of the PHLX currency options market. Journal of Banking and Finance, 19, 803-821. http://dx.doi.org/10.1016/0378-4266(95)00086-V 


\section{Appendix}

IDIV is the volatility that is implied by the intra-daily options market price using the options pricing model. Black and Scholes (1973, BS) first derive a closed-form solution for pricing European options. The BS model assumes that no dividends are paid on the stock during the life of the option. Merton (1973) extends this model to cover continuous dividends. Since the interest gained on holding a foreign security is equivalent to a continuously paid dividend on a stock, the Merton version of the BS model can be applied to a foreign security. To value the currency option, stock prices are substituted for exchange rates. Following Biger and Hull (1983), the price of a European-type call and put option on currency is given in Equations (A1) and (A2), respectively,

$C_{i}=S_{i} e^{-R_{t}^{f} T} N\left(d_{1, i}\right)-X_{i} e^{-R_{t}^{d} T} N\left(d_{2, i}\right)$,

$P_{i}=X_{i} e^{-R_{t}^{d} T} N\left(-d_{2, i}\right)-S_{i} e^{-R_{t}^{f} T} N\left(-d_{1, i}\right)$,

where,

$d_{1, i}=\frac{\ln \left(S_{i} / X_{i}\right)+\left(R_{t}^{d}-R_{t}^{f}+\sigma_{i}^{2} / 2\right) T}{\sigma_{i} \sqrt{T}}$ and

$d_{2, i}=\frac{\ln \left(S_{i} / X_{i}\right)+\left(R_{t}^{d}-R_{t}^{f}-\sigma_{i}^{2} / 2\right) T}{\sigma_{i} \sqrt{T}}=d_{1, i}-\sigma_{i} \sqrt{T}$.

The notations of Equation (A1) and (A2) and their descriptions are as follows:

C

$P$

$\mathrm{S}$

$\mathrm{X}$

currency

$\mathrm{R}^{\mathrm{d}}$

$\mathrm{R}^{\mathrm{f}}$

$\mathrm{T}$

$\sigma$

$\mathrm{N}(\cdot)$ call option price in domestic currency

put option price in domestic currency

spot price in domestic currency

option exercise price in domestic

domestic currency interest rate

foreign currency interest rate

option maturity period

volatility of underlying currency

cumulative normal distribution function

For notation convenience, let $\xi_{t}=e^{-R_{t}^{f} T}$ and $\eta_{t}=e^{-R_{t}^{d} T}$, so that Equations (A1) and (A2) can be written as follows:

$C_{i}=S_{i} \xi_{t} N\left[d_{1, i}\left(\sigma_{C, i}\right)\right]-X_{i} \eta_{t} N\left[d_{2, i}\left(\sigma_{C, i}\right)\right]$,

$P_{i}=X_{i} \eta_{t} N\left[-d_{2, i}\left(\sigma_{P, i}\right)\right]-S_{i} \xi_{t} N\left[-d_{1, i}\left(\sigma_{P, i}\right)\right]$

The IV $\sigma_{\mathrm{C}, \mathrm{i}}$ and $\sigma_{\mathrm{P}, \mathrm{i}}$ provide the market call and put price, respectively, when they are substituted into Equations (A3) and (A4). It is not possible to invert Equations (A3) and (A4) with respect to $\sigma_{\mathrm{C}, \mathrm{i}}$ and $\sigma_{\mathrm{P}, \mathrm{i}}$, respectively. The iterative search procedure can be an alternative method for computing the IV for given options market prices. 
Hoque \& Kalev | Pricing Currency Options with Intra-Daily Implied Volatility 